jigns-i. e., by excluding other causes. As a general rule the younger the child, and the more "neurotic" the disposition, the more likely is the pyrexia to be functional. But in the prolonged form there are certain characteristics which occasionally help to distinguish it: (1) extreme irregularity of temperature, rapid alternations of high and low ; (2) fluctuations of temperature not agreeing in time with the usual diurnal maximum and minimum; and (3) absence often of the constitutional disturbance which would be associated with an equally prolonged symptomatic pyrexia. The pyrexia of dentition often illustrates these points well, and further show the influence of age in the much greater frequency of its occurrence in the first dentition than in the second.

In conclusion I should like to point out that, while I believe many of the obscure pyrexial attacks of childhood to be rightly explained only by the above theory, I do not in the Ieast wish to call every pyrexial attack for which no cause is found an instance of functional ataxic pyrexia ; many remain, and always will remain, clinical mysteries, which doubtless would often be solved if the subsequent histories could be traced, or the connexion proved with those old pleuritic adhesions, those calcified glands, or those fibroid patches in the lung which are so often found post mortem, the only record of unsuspected disease in bygone years.

Wray-crescent, Tollington-park, N.

\section{THREE CASES OF ANEURYSM TREATED BY VENESECTION.}

BY JAMES T. R. DAVISON, M.D. EDIN., GORMERLY RESIDENT PHYSICIAN TO THE EDINBURGH ROYAL INFIRMARY.

BLEEDING in the treatment of aneurysm is a measure which, in the present day, is discredited. This is due to the abuse to which the mode of treatment was carried in days gone by. That bleeding judiciously employed is a most valuable element in the treatment of aneurysm the following cases appear to me to testify.

CASE 1.-A man forty years of age, without syphilitic or alcoholic antecedents, had been for a year subject to fatigue on undergoing certain exertions, when, in June, 1891, while on a voyage to Europe and in the act of playing cards, he was seized with a sudden attack of dyspncea, which ended in loss of consciousness. Three days afterwards he landed in Spain, where he remained a fortnight, during which time he had several attacks of dyspnœa, but only once lost consciousness. He afterwards went to Paris, where he consulted a physician, who diagnosed a sardiac affection due to smoking, and advised him to go to Bourboule and take there the arsenical waters. He remained at Bourboule a month, during which time he was free from his former attacks. He then returned to Paris, where he sought the advice of Dr. Potain This physician diagnosed dilatation of the aorta and insufficiency of the aortic valves, and ordered him, in sernally, iodide of sodium and some external applications. He remained in Paris five months free from his attacks. Subsequently he returned to Spain, when he was again seized with paroxysms of dyspnœea. After sojourning three months in that country he returned to Buenos Ayres. During the voyage he had no attacks, but on arriving here the paroxysms of dyspncea returned again. As the result of a consultation which was beld on his behalf he was put upon an absolute milk diet. After this he became considerably worse. On June 10th and 11th, 1893, he had several attacks. On the 12th I was asked to see him in consultation with otber colleagues. I diagnosed aneurysm of the aorta, compressing the recurrent laryngeal nerve, and advised amongst other things suppression of the absolute milk diet and an extraction of blood from his arm. That same evening he had a very severe attack. When I arrived at his house, accompanied by one of his medical attendants, I found him with loss of oonsciousness and great difficulty of breathing, his face was cyanotic, and his pulse had a high tension. In the confusion of the moment a member of the family had administered one or two hypodermic injections of morphia. Then and there we bled him from his arm, taking away thirty ounces if blood. His breathing then became easier, the cyanotic hue of his face began to disappear, the high tension of his pulse fell, and when he regained consciousness he found himself without fatigue, and without fatigue he has remained until this day-a period of nine months. He now feels perfectly well, and is about to make a voyage of pleasure to Europe. The medicinal treatment to which his medical attendants subjected him all this time has been the administration of iodide of sodium three weeks each month, and a cantharides blister over the aneurysm continually, as recommended by Dr. Potain. I had an opportunity of examining the patient nine months after he was bled--and the following was his condition then: the pulse was regular, strong, rather full, and very difficult of compression; the cardiac impulse was strong and pushing; the apex beat was in the sixth interspace, about one inch outside the mammillary line; there was longitudinal dulness; resonance was impaired at the fourth rib; at that level there was no increase of trans. verse dulness. Mitral area: the first sound was of low pitch and strong intensity; a weak blowing murmur replaced the second sound. Tricuspid area: the first sound was normal; the second sound was replaced by a weak blowing murmur. In the aortic and pulmonary areas the first sound was weak, the second being renlaced by a weak blowing murmur. There was no accentuation of the second sound anywhere. On the right side, over the inner part (about two inches) of the first rib, the first interspace, and the second rib, the resonant note on percussion was manifestly impaired; over this area a pulsation was seen and felt. Here also the two sounds of the heart were heard, but they were weak, and the second was also impure. Pressing behind the manubrium sterni a pulsation was felt, though low down. The sign known as the "tracheal tug" was felt very distinctly. Behind, the respiration over the left interscapular space was less distinct than on the corresponding right side ; the percussion note was there resonant.

In this case the position occupied by the pulsating area points to aneurysm of the innominate artery and ascending aorta; the tracheal tug and the diminution of respiration over the left interscapular space point also to dilatation of the transverse arch. The first aneurysm would be in a position capable of compressing the right pneumogastric just before it gave off the recurrent laryngeal, and the second would press the left recurrent laryngeal. The attacks might then have been due to dilatation of one or both aneurysms. The weakness of the first sound at the base, the absence of the second, and its replacement by a weak blowing murmur, when elsewhere there is evidence of a large heart pulsating strongly, indicate that the first aneurysm has removed somewhat the base of the heart from the anterior wall of the thorax. The weakness of both sounds over the aneurysmal space, in spite of the energetic action of a hypertrophied heart, indicates that the medium between the internal part of the aneurysm and the chest wall is not favourable for the conduction of sound; in other words, it presumes that coagulation has taken place within the sac, and that possibly also the walls have undergone thickening. This case illustrates well the benefit of bleeding in the treatment of aneurysms. Here, as a result of this measure, the aneurysm or aneurysms contracted ; thereby the symptoms of compression were relieved and the aneurysms were placed under more favourable conditions for the operation of other therapeutic means destined to consolidate them. The aortic insufficiency in this case was of no moment, as compensation was established.

CASE 2. - This case was that of a patient forty-four years of age, who about the month of January, 1893, began to notice that, after undergoing any slight exertion or annoyance, both sides of his neck swelled. On one of these occasions, while looking at himself in a mirror, he found that his face was purple and swollen. He stated that about the same time he began to feel some uneasiness in swallowing. In the month of August he began to feel great pain over the left hypochondrium, both shoulders, and back. In September his right arm began to swell. He never complained of fatigue and slept well on either side when he had no pains. This patient has had syphilis and up to four years ago had suffered from asthma for twenty years. Four years ago he bad influenza and pneumonia, and since then his asthma disappeared. I saw this patient in consultation on Oct. 23rd, 1893. His face was then purplish-blue, his neck and right arm being very swollen. I advised that he should be bled, and on the same day twenty-seven ounces of blood were taken from both arms. At the end of the operation he fainted, but was immediatel brought to by slapping a wet towel on his face. The effects of the bleeding were very marked. The pains disappeared immediately, and next day the swelling of the arm and neck 
had to a great extent disappeared. This patient, owing to his personal affairs, could not undergo proper treatment. A month after the bleeding he was obliged to be up and doing, and has had daily to mount several flights of stairs in different houses. He also at first was unable to take iodide of potassium except for a short time, and in very small doses. The last two months he has begun to take iodide again. In spite of the unfavourable circumstances for treatment in which this patient was placed, fire months after the bleeding he was a different man altogether. His right arm bas lost its swelling, his face has lost its purple colour, and the swelling of the neck has greatly diminished. Three months after the bleeding pain came on over the aneurysm; this pain he has had to combat with other means. An examination made on Jan. 30th, 1894, gave the following signs :- Examined after dinner: pulse regular, strong, normal size, inclined to be incompressible ; right one appears somewhat less than left. Heart impulse not felt (he is a small, stout man). Cardiac beat not discernible. Longitudinal dulness at fourth rib. In mitral and tricuspid areas sounds were normal. In aortic and pulmonary areas the first sound was normal, the second somewhat accentuated. There is dulness at the inner part of the second right interspace, and loss of resonance over the corresponding upper and lower ribs. Pulsation was felt over the inner part of the right second interspace; over this area was heard a systolic murmur (not very distingurshable as a murmur) and a well-accentuated second sound. There was fulness over the right supra-clavicular space. The external jugular vein (right) was full. The superficial veins of the upper part of the chest in front were dilated, especially the right side. In this case there appeared to be an aneurysm of the ascending aorta and innominate artery, compressing the innominate veins, especially the right, and compressing somewnat the right subclavian artery; also some dilatation of the transverse arch, affecting the csophagus. Had this patient been in a position to undergo a thorough treatment probably the good effects produced would have been much greater; as it was, the relief of compression of the innominate veins was very marked.

CASE 3.-The patient in this case was seen by me in June, 1891. He then had impairment of resonance or percussion over the sternal end of the left first interspace, and over this area there was visible pulsation. The second sound at base was of a thumping character, and over the pulsating area the same character of the sound was present. The tracheal tug was well marked. The right radial pulse was almost imperceptible. His symptoms were coldness of right arm, pain over the præcordia and corresponding right side, pain and difficulty in swallowing liquids, and hoarseness of voice. He had had buboes six years ago, left hemiplegia four years ago, lasting three weeks, and was operated on for popliteal aneurysm three years ago. This case, which appears to be one of aneurysms of the ascending and transverse aorta, was under treatment for several months with marked benefit to his symptoms. Fighteen months after I first saw him he had an attack of sneezing, which was followed by inability to swallow solids; when he swallowed liquids a gurgling noise was heard at a distance from him. At the same time his pains became worse. I bled him from the arm, and immediately the difficulty of swallowing and the pains disappeared. This patient, who continually took iodide of potassium, went on pretty well for another year, when after another fit of sneezing he felt as "if he had been shot," the pain being so intense that he could not speak for two or three minutes; after two or three days he again had difficulty in swallowing. I took twenty-five ounces of blood from his arm. This time the symptoms abated, but only after a few days. This was about four months ago. I saw him again last week; he is going about pretty free from symptoms, but on examination I find that the aneurysm of the transverse arch is larger than it was in 1891, for now the respiration of the left lung is less than on the right side, showing that the left bronchus is being invaded.

In this case the relief from symptoms of compression was immediate and very marked after the first bleeding. The effects after the second bleeding were less marked, but a whole year had elapsed, and in this interval the evolutionary shanges in such an aneurysmal diathesis which were taking place must have destroyed in a great measure the contractile elements of the sac.

Bleeding in the treatment of aneurysm is no innovation. It was, even according to Dr. Balfour, ${ }^{\mathrm{l}}$ suggested by

1 Diseases of the Heart, flirst edition, p. 364.
Hippocrates, and it formed the basis of the celebrated treatment of Valsalva-a treatment which fell into discredit owing to the abuse of bleeding which it advised and because, at the same time that it tended to consolidate the aneurysm, it also tended to prevent this consolidation. Medical literature presents cases where spontaneous rupture of aneurysms has been followed by contraction of the sac, relief of symptoms of compression, healing of ruptured wound, and apparent prolongation of life. If such benefit can follow the spontaneous rupture of an aneurysm may not the same benefit be obtained by the harmless extraction of blood from a vein? The abuse of a remedy is not a sufficient cause for excluding its legitimate use, nor must the intelligent physician be bound by the fashion of the day, which at one time decrees abuse of bleeding and at another time its total rejection.

The dilatation of an aneurysm is produced by the pressure of the blood stretching its coats weakened by disease. If these coats retain contractile elements, it is evident that a diminution of the volume of blood within the aneurysm, together with a diminution of the pressure of the blood if carried to a sufficient extent, will enable the aneurysm to contract; but the lowering of blood pressure after hæmorrhage is only temporary, and after a short time this pressure regains its former force. Does it, then, follow that conjointly with the return of the force of the blood pressure the aneurysm will again dilate to its former extent, and thas bleeding come to be of no value? Certainly not, for in order that the aneurysm may return to its former degree of dilatation it is necessary either that in a few days changes shall take place within its walls, lessening their power of resistance, or that the blood pressure shall attain to a degree which it had not reached before; for if, before, a certain amount of blood pressure was necessary to keep the aneurysm in its over-distended state, now that it has contracted, to keep it again stretched as before, would require the same amount of blood pressure that maintained it distended, plus another quantity necessary to overcome the contractility of the walls now contracted, and therefore in more favourable conditions to overcome resistance. It follows, therefore, that when the walls of an aneurysm retain a sufficient quantity of contractile elements the contraction which will take place on lessening the volume and the pressure of the blood, after a good bleeding, may, with judicious care, be maintained, even after the blood pressure has regained its former strength. In the treatment of aneurysms three principles must be kept in view-the contraction of the aneurysm, the hypertrophy of its walls, and lastly the deposition of fibrin within its cavity. The first indication can be carried out by a copious depletion, together with absolute rest for several months and the ingestion of but a limited amount of liquids. The second indication can be carried out by the internal administration of iodide of potassium, as recommended by Dr. Balfour, avoiding excessive doses, which may accelerate the pulse. The third indication requires, in addition to the above measures, a diet which, without being very rich to stimulate anduly the circulation, will at the same time be nutritive enough to produce a sufficient quantity of fibrin. The principle which I advocate here in the treatment of aneurysms is not the impoverishment of the blood, but the temporary diminution of its volume and of its pressure, so as to enable the aneurysm to contract and place it thus under circumstances more favourable for the operation of other remedial agents which tend towards its consolidation. Repeated bleedings at short intervals have been known to be positively harmful; but keeping in mind the above principle the intelligence of the physician will indicate when and how to bleed. Judicious bleeding in the treatment of aneurysms will prove to be a valuable element, by means of which alarming symptoms of compression may be quickly removed, instant death sometimes averted, and the patient placed under favourable conditions for the prolongation of his life.

Buenos Ayres.

The committee of the Gipsy Hill and Upper Norwood Dispensary in their twenty-sixth annual report call attention to the large falling-off in subscriptions for the year 1893.

Mr. Alexander Wynter Bryth, who has held the post of medical officer of health for the vestry of St. Marylebone during the past fourteen years, is to be presented by that body with a public testimonial to the services that he has rendered to the parish during the late epiclemic of scarlet fever and diphtheria. 


\section{THE MOR'TALITY UNDER THE CASAREAN OPERATION IN GREAT BRITAIN DURING THE LAST EIGHT YEARS ;}

AND THE ENCOURAGEMENT OFFERED FOR THE INTRODUCTION OW SYMPHYSIOTOMY AS A SUBSTITUTE FOR CRANIOTOMY.

By ROBERT P. HARRIS, A.M., M.D.

BEFORE discussing the relative merits of these two operations and their risks respectively, it may be well to consult the British records of the former for the period since the improved method of performing it was in a measure introduced in 1886, as there is evidently in London a prevailing error as to what has been accomplished in the saving of life in Great Britain. When we look back to the early record of Dr. Thomas Radford, with its 84 per cent. of maternal deaths, and compare it with the results of cases we have recently collected, we find much ground for encouragement, although it is evident that much more might be accomplished in reducing the death-rate. The Cæsarean operation early performed, or done before labour, upon a good subject, has a much lower rate of mortality than when the woman has been exhausted by a long labour, and especially where the numerous attempts have failed to deliver under the forceps, version, or craniotomy. When we group together all of the cases recorded for a given country and state how many died and how many recovered we get a very imperfect idea of the danger of the operation per se. We have a general knowledge of the risk, but what we. require to look into and know is why one died and another did not; and it is the acting out of this knowledge that will eventually reduce the death.rate to a moderate percentage. If men had less fear of the operation it would be undertaken in good season and result in fewer deaths. In order to find what has been the amount of loss in England and Scotland since Nov. 1st, 1886, we made a careful search for all of the published cases and obtained the followingviz.: for London, 22 operations-women died, 9 ; children lost, 5. For Glasgow, 32 operations-women died, 5; children lost, (?). ${ }^{1}$ For the provincial towns, 6 caseswomen died, 5; children lost, 3; making a total of 60 operations with 41 recoveries and (?) ${ }^{1}$ children saved, a mortality of nearly 32 per cent. of the cases, London losing 40 per cent. Not being able to obtain the unpublished operations we have failed to give a full list, but the proportion would not probably be materially altered. Our record, published and not published, for the United States, commencing with 1882 - the year the improved operation was introduced-now shows 100 operations with 38 deaths. Out of the first 5024 died, and of the second 50 14 died. There were 16 operations in 1893 with 4 deaths. This shows that there is no difference in the results of the two countries; both are far from creditable and might be made much more so. Our cities should at least do much better, and try to make some approach towards the successes of Leipzig and Dresden. Philadelphia has made a step forward by saving 13 women and 14 children under her last 16 operations; 2 of the 3 deaths were in cases having very unfavourable prognoses. When we come to examine the dangers and results of symphysiotomy, where it has been carefully and thoroughly tested, we find a more encouraging record. Prof. Paul $Z_{w}$ eifel of Leipzig has given both operations an extended trial, with the following results : by the Cæsarean operation be lost the fourteenth and twentieth cases out of a total of 30 ; and under 23 symphysiotomies he lost 2 children, but no woman. We know of no fairer comparative test than this, as the same operator made both trials. We have had 44 symphysiotomies in the United States, with a loss of 5 women and 11 children, 5 of the latter having been already dead before the operation. Compare this with our last 44 Cæsarean sections, and we find: women lost 12, and children lost 12. Mortality of women under symaphysiotomy, $11_{1 \mathrm{4}}^{4}$ per cent., and under the Cæsarean section, $27 \frac{3}{11}$ per cent., or more than double. A great deal has been said about the disabilities produced by symphysiotomy, but we have found very little of any form here. As the children delivered in our country under this operation

1 We have not the results as to the children in 20 of Professor Murdoch Cameron's cases ; under the other 40 operations there were 9 lost. have averaged $81 \mathrm{~b}$, we propose to limit the conjugata vera to $2 \frac{3}{4}$ in. The Italian subosseous method we believe to be the best form of operation. In primipara the Neapolitan operators secure safety to the soft parts by letting the woman in many cases deliver herself. At one time three out of fors women were left to nature after the section; but now delivery by the forceps is much more common. With proper care there should seldom be any strain upon the pelvis or injury to the vagina or bladder. Women have in a number of instances been operated upon twice, and one subject in Philadelphia has been delivered of living children, once by the Cæsarean operation and twice by symphysiotorny. She would not consent to any sterilising method being made use of. The last 28 symphysiotomies in the United States proved fatal to but two women, or $7 \frac{1}{7}$ per cent. It will be a long time before the Cæsarean operation can accomplish this, in either England or America. When we can average 15 per cent. we may feel encouraged. Single operators like Prof. Cameron may save 90 per cent.; but in general practice we do not expect so low a death-rate as one in ten.

Philadelphia.

\section{A SUGGESTION FOR INCREASING THE POPULARITY AND EFFICIENCY OF VACCINATION.}

BY G. E. YARROW, M.D. HeIDELB., L.R.C.P. D P.H. LOND., \&c.,

MEDICAL OFFICER OF HEALTH FOR ST. LUKE, MIDDLESEX, ANT SURGEON ACCOUCHEUR AND LECTURER ON MIDWIFERY TO THE CITY OF LONDON LYING IN HOSPITAL.

AT a time when small-pox is beginning again to manifest itself throughout the country the attention of those engagec in the practice of preventive medicine is naturally directed to a consideration of the means at their command to avert as much as possible so formidable a disease becoming epidemic, to try to discover the weaknesses (if any) which exist in connexion with such means, and to consider in what direction they may be strengthened. Imbued with these views, and with no desire to be dictatorial, I venture to assert: First, that vaccination has from various causes become most unpopular, and its unpopularity is daily increasing, particularly amongst the lower middle and lower classes. Secondly, that the bulb of the vaccination now performed (in London at least) is most inefficient, as far as its value from a protective point of view is concerned, this latter defect depending almost wholly upor the first ; and I am sanguine enough to believe that if these defects can be remedied the compulsory clauses of the Vaccination Act will be no longer necessary, and another stumbling. block in the way of its acceptance as a beneficent measure will be removed. The remedy, I venture to suggest, is to allow every registered practitioner to vaccinate and claim through the sanitary authority a fee of $2 s .6 d$. for each certificate of successful vaccination furnished to the said authority, as is now the practice in regard to the notification of infections diseases. The certificate should specify the number of separate insertions of lymph or area over which the effect is produced, and, a standard being fixed, only such results as reached the standard should be regarded as efficient vaccination to be paid for by the sanitary authority. Of course this will necessitate an increased amount of supervision, to which honourable medical practitioners surely will not object, and the unscrupulous need not have much consideration bestowed upon them. I would further remind those likely to object that at the present time when a vacancy occurs in the office of public vaccinator there is no lack of candidates, and one never yet heard of the objection being raised by an aspirant for the post to his work being under the supervision of an inspector of the Local Government Board. I believe that if vaccination were performed under the conditions I propose it would be regarded more in the light of a public duty than it is at present, bringing in its train, amongst other responsibilities, the liability to the work being inspected. The worse than useless vaccinations, and the unnecessary and harmful postponements for which cheap dispensaries are largely responsible, together with the needless, if not mischievous, Form $B$ in the present vaccination certificates, will become things of the past. Daring my twenty years' experience as a public vaccinator I bad my fuli share of difficulties to contend with, but I found none greats 